\title{
约 \\ CONDICIONANTES POLÍTICOS NO SUCESSO LEGISLATIVO DOS GOVERNADORES BRASILEIROS: UMA ANÁLISE COMPARATIVA QUALITATIVA (QCA)
}

\author{
POLICY CONDITIONS IN THE LEGISLATIVE SUCCESS OF BRAZILIAN \\ GOVERNORS: A QUALITATIVE COMPARATIVE ANALYSIS (QCA)
}

\author{
CONDICIONES POLÍTICAS EN EL ÉXITO LEGISLATIVO DE LOS \\ GOBERMADORES BRASILEÑOS: UN ANÁLISIS COMPARATIVO CUALITATIVO \\ (QCA)
}

\begin{abstract}
Resumo: O presente artigo verifica quais são as condições políticas/contextuais que possibilitam aos governadores brasileiros obterem resultados satisfatórios na condução da sua agenda legislativa. Para empreender tal análise, foi desenvolvido um indicador alternativo de sucesso legislativo do Executivo: o Índice de Poder Legislativo do Executivo (IPLE). Espera-se que tal índice varie em função de combinações entre o tamanho da oposição $\left(\mathrm{x}_{1}\right)$; a fragmentação da assembleia $\left(\mathrm{x}_{2}\right)$ e; a polarização ideológica da assembleia $\left(\mathrm{x}_{3}\right)$. Através da análise Comparative Qualitative Analyses (QCA) foram examinados o processo legislativo em nove Assembleias Legislativas em duas legislaturas. Os principais achados são: i) que tamanho da oposição é condição necessária para o sucesso legislativo e; ii) o sucesso na condução de sua agenda ocorrerá em $60 \%$ dos casos em assembleias sem oposição e com baixa fragmentação.
\end{abstract}

Palavras-chave: Assembleias Estaduais; Governadores; Sucesso Legislativo; IPLE; QCA.

\begin{abstract}
This article verifies what are the political / contextual conditions that enable Brazilian governors to obtain satisfactory results in the conduct of their legislative agenda. To undertake such an analysis, an alternative indicator of legislative success for the Executive was developed: the Executive Legislative Power Index (IPLE). It is expected that this index will vary depending on combinations between the size of the opposition (x1); fragmentation of the assembly (x2) and; the ideological polarization of the assembly (x3). Through the Comparative Qualitative Analyzes (QCA) analysis, the legislative process in nine Legislative Assemblies in two legislatures was examined. The main results are: i) what size of opposition is a necessary condition for legislative success and; ii) the success in carrying out its agenda will occur in $60 \%$ of the cases in assemblies without opposition and with low fragmentation.
\end{abstract}

Keywords: Legislative Assemblies; Governors; Legislative Success; IPLE; QCA.

Resumen: Este artículo verifica cuáles son las condiciones político/contextuales que permiten a los gobernadores brasileños obtener resultados satisfactorios en el desarrollo de su agenda legislativa. Para realizar dicho análisis, se desarrolló un indicador alternativo de éxito legislativo para el Ejecutivo: el Índice de Poder Legislativo Ejecutivo (IPLE). Se espera que este índice varíe dependiendo de las combinaciones entre el tamaño de la oposición (x1); fragmentación de la asamblea (x2) y; la polarización ideológica de la asamblea (x3). A través del análisis de Análisis Cualitativo Comparativo (QCA), se examinó el proceso legislativo en nueve Asambleas Legislativas en dos legislaturas. Los principales hallazgos son: i) qué tamaño de oposición es una condición necesaria para el éxito legislativo y; ii) el éxito en la ejecución de su agenda se dará en el $60 \%$ de los casos en asambleas sin oposición y con baja fragmentación.

\footnotetext{
${ }^{1}$ Professor da Universidade Federal de Alfenas (UNIFAL-MG). O autor agradece as críticas e sugestões feitas pelos pareceristas. Quaisquer erros e/ou omissões são de inteira responsabilidade do autor. ORCID: 0000-0001-7018-5694. E-mail: thiago.silame@gmail.com ou thiago.silame@unifal-mg.edu.br.
} 
Palabras clave: Asambleas Estatales; Gobernadores; Éxito Legislativo; IPLE; QCA.

\section{Introdução}

O presente artigo insere-se na área dos estudos legislativos tendo como objeto de estudo as assembleias legislativas brasileiras (ABRÚCIO, 1998, SANTOS, 2001; TOMIO e RICCI, 2012a, 2012b, SANTOS e ANASTASIA, 2016; SILAME, 2018; TOMIO e RICCI, 2018). O foco incidirá sobre a relação entre o poder Executivo e Legislativo, visando verificar a força legislativa dos governadores. O artigo analisa dados sobre a produção legislativa em nove estados brasileiros durante duas legislaturas ${ }^{2}$. Ademais o artigo propõe um indicador alternativo para se medir o sucesso legislativo do Executivo.

Santos (2001) e Tomio e Ricci (2012b; 2018) destacam a diversidade nos padrões de relação entre o Executivo e o Legislativo. Na coletânea organizada por Santos (2001) há a observação de parlamentos ativos que podem colocar anteparos à vontade do Executivo, além da existência de Legislativos que apresentam uma agenda própria e padrões que remetem ao ultrapresidencialismo (ABRÚCIO, 1998). Tomio e Ricci (2012b) destacam o alto sucesso legislativo dos Executivos estaduais (média de 87\%) e uma baixa dominância (média de 27\%). Para os autores uma das possibilidades de explicação da variação das taxas de sucesso executivo remete à necessidade de se compreender as dinâmicas político-partidárias em cada estado (NUNES, 2008). Isto posto, a pergunta que orienta este artigo pode ser formulada nos seguintes termos: Quais são as condições políticas/contextuais que possibilitam aos governadores brasileiros obterem sucesso legislativo? O trabalho assume que o tamanho da oposição, a fragmentação e polarização ideológica nos parlamentos explicam a variação do sucesso legislativo do Executivo no tempo e espaço, uma vez que configuram vários contextos.

O presente artigo está estruturado em cinco seções e considerações finais. A primeira seção apresentará uma não exaustiva revisão da literatura sobre a relação entre os o Executivo e Legislativo nos estados brasileiros. A segunda seção tem como intuito apresentar o Índice de Poder Legislativo do Executivo (IPLE), indicador alternativo para mensurar o sucesso legislativo dos governadores. A terceira seção explora dados referentes à produção legislativa nos estados considerados. Na quarta seção será realizada a calibragem do resultado de interesse (Sucesso Legislativo do Executivo) e das variáveis políticas (fatores causais) consideradas. A última seção tece a análise sobre o sucesso legislativo dos governadores à partir da técnica conhecida como Comparative Qualitative Analyses (QCA). Por fim as considerações finais.

\section{1 - A relação executivo-legislativo nos estados brasileiros}

A presente seção tem como objetivo apresentar, de maneira não exaustiva, parte da

\footnotetext{
2 São considerados os estados da Bahia, Ceará, Minas Gerais, Pará, Pernambuco, Rio de Janeiro, Rio Grande do Sul, Santa Catarina e São Paulo nas legislaturas 2007/2011 e 2011/2015.
} 
literatura que aborda o tema da relação entre o Executivo e o Legislativo nos estados brasileiros pós redemocratização ${ }^{3}$. Em "Barões da Federação", Abrucio (1998), ao analisar a relação executivo e legislativo em diversos estados, cunhou o termo "ultrapresidencialismo estadual". Segundo o autor, tal fenômeno se caracteriza por uma dominância completa do executivo sobre o processo legislativo, além da anulação de mecanismos de check and balances. Governadores deteriam recursos diversos que lhes possibilitavam contar com maiorias inorgânicas. Em síntese, de um lado o governador com a chave do cofre e do outro lado parlamentares interessados única e exclusivamente em alocar recursos em suas bases eleitorais no intuito de alavancar suas carreiras políticas. Logo, as assembleias apresentam uma lógica governista ${ }^{4}$, onde vigora um "pacto homologatório", sendo submissas ao executivo.

O trabalho seminal de Abrucio serve como referência para as demais produções que se seguiram e diversos autores propõe um diálogo crítico com a obra do autor. Santos (2001a) organiza uma coletânea a fim de observar se a lógica do "ultrapresidencialismo" ainda se faz presente na relação Executivo-Legislativo nos estados. A análise empreendida para diversos estados mostra que duas assembleias apresentaram tal padrão. Este padrão foi observado por Domingues (2001) para o Espírito Santo, e por Abrucio et. al. (2001) para São Paulo. Outros estados apresentaram assembleias legislativas com autonomia e independência, os casos da Assembleia Legislativa de Minas (ALMG) e a Assembleia Legislativa do Rio de Janeiro (Alerj) observados, respectivamente por Santos (2001b) e Anastasia (2001). Um terceiro conjunto de estados que contempla o Ceará e o Rio Grande do Sul apresentou uma dinâmica informada pela disputa político-partidária nos estados que se consubstancia pela ação de situação e oposição no parlamento (MORAES, 2001; GROHMANN, 2001), portanto, não subservientes ao executivo. Os achados da coletânea organizada por Santos apresentam diversidade e convergência em relação ao fenômeno do "ultrapresidencialismo".

O fato é que a reforma do Estado brasileiro, as políticas de privatizações e a entrada em vigor da Lei de Responsabilidade Fiscal (LRF), que ocorreram ao longo da década de 1990, retiram dos governadores recursos que os permitiam colocar sob seu jugo as assembleias. O que tornaria a tese do "ultrapresidencialismo" datada.

Contudo, ainda é possível perceber nos estados do Pernambuco, Espírito Santo e Maranhão a vigência do "ultrapresidencialismo" (LEITE e SANTOS, 2010; RAINHA, 2018; BORGES, 2018), portanto, pode-se toma-lo como uma das formas de relação existentes entre o executivo e o legislativo, uma vez que a literatura observada aponta variações na forma de como

\footnotetext{
${ }^{3}$ A primeira eleição direta para governadores de estado se deu no contexto de abertura política em 1982. Pode-se tomar como marco histórico da transição da ditadura para a democracia a promulgação da Constituição de 1988 seguida das eleições diretas para presidente em 1989. As obras analisadas contemplam em sua grande maioria o período pós 1988. ${ }^{4} \mathrm{O}$ autor faz uma diferenciação entre situacionismo e governismo. Para Abrucio o situacionismo abarca os parlamentares que participam da bancada do governo. O governismo é um fenômeno maior que envolve praticamente todos os deputados interessados em obter um "naco de patronagem" junto ao poder Executivo. Tal fenômeno chama a atenção, pois Abrucio observa que mesmo governos minoritários conseguiam aprovar a sua agenda.
} 
se dá o apoio aos governadores. Trabalhos posteriores aos publicados no volume organizado por Santos (2001a) também apresentam as outras duas variantes de relação entre o Executivo e o Legislativo. Uma dinâmica que aponta um protagonismo legislativo dos parlamentares na condução de uma agenda própria (TOMIO e RICCI, 2012a e 2018b, BRAGA e FRANÇA, 2008. TOMIO e MIRANDA, 2018; GRAÇA e PINTO, 2018) e outra dinâmica relacionada a construção partidária de apoio ao Executivo nos estados (NUNES, 2008; PERONDI e CARREIRÃO, 2009; TOMIO e MIRANDA, 2018).

Ponto comum aos diversos trabalhos mobilizados nesta seção é a alta taxa de sucesso legislativa do executivo, apontada muitas vezes como evidência do "ultrapresidencialismo". Entretanto, a mera observação da aprovação da agenda dos governadores pode ser uma miragem, uma vez que ela é pouco conflitiva por ser constrita pela Constituição Federal de 1988. Cabe aos estados legislarem de forma concorrente e complementar com a União e municípios sobre matérias relacionadas a políticas públicas (saúde e educação) e de forma exclusiva sobre assuntos administrativos, financeiros e tributários. As altas taxas de sucesso legislativo de projetos oriundos do executivo, dizem mais respeito à natureza da agenda estadual do que a uma subserviência do Legislativo. Seja como for, neste cenário de protagonismo legislativo do executivo que se dá em torno de uma agenda administrativa do estado, é mais racional ao parlamentar delegar poderes para o executivo e orbitar em torno de um governo bem-sucedido (ABRUCIO et. al, 2001; NUNES, 2008; LEITE e SANTOS, 2010; ARAÚJO, 2016; TOMIO e RICCI, 2012a; 2018a).

Outro ponto em comum dos trabalhos mobilizados é evidenciar que a agenda aprovada pelo Legislativo é de baixa relevância e visa a concentrar recursos nas bases eleitorais dos parlamentares. Entretanto, isto não significa uma corroboração da tese do "ultrapresidencialismo", uma vez que diversos trabalhos apontam que a despeito da agenda de cunho clientelista aprovada pelos parlamentares nas assembleias estaduais há uma agenda de políticas públicas desejadas e perseguidas pelo Legislativo ainda que não alcançada (ANASTASIA, 2001; SANTOS, 2001b; CERVI, 2009; TOMIO e RICCI, 2010; 2012a; 2012b; GRAÇA e PINTO, 2018).

Alguns trabalhos que apontam para suplantação da dinâmica do "ultrapresidencialismo" como forma de relação entre o Executivo e o Legislativo destacam o comportamento de bancadas disciplinadas nas assembleias de Minas Gerais e Santa Catarina (NUNES, 2008; CARREIRÃO e PERONDI, 2009). O caráter orgânico - mediado pelos partidos políticos - do comportamento parlamentar é um forte indicio contrário à tese do "pacto homologatório".

Ademais as assembleias estaduais congregam deputados com interesses diversos que podem atuar de forma a maximizar uma agenda particularista ou mais universalista. Perceber os microfundamentos que informam o comportamento legislativo dos atores políticos é fundamental para se debater a tese do "ultrapresidencialismo estadual". É de se esperar que assembleias que 
apresentem um comportamento mais particularista dos parlamentares seriam pautadas pela atuação individual e, portanto, menos partidária, criando condições favoráveis para a vigência do governismo.

Diversos trabalhos apontam que o comportamento dos deputados estaduais varia em função do nível de competitividade eleitoral e parlamentar nos estados, estruturação dos subsistemas partidários, assim como, a ideologia pode definir se a atuação do parlamentar será mais voltada para a sua base ou será mais abrangente em termos de proposições (CASTRO et. al, 2009; CERVI, 2009; INÁCIO e AMARAL, 2013; MELO, 2011; 2015). Os trabalhos também demonstram que a variação observada nas taxas de sucesso do Executivo pode ser explicada a partir das motivações mais ou menos particularistas dos agentes políticos. O comportamento distributivo dos parlamentares associado à rede de apoios locais que os mesmos possuem induz a uma aproximação dos deputados com o Executivo (INÁCIO e AMARAL, 2013). Segundo os autores existem espaços para atuação independente ou de oposição dos parlamentares a depender do grau de competitividade dos subsistemas partidários. Sistemas partidários e eleitorais estáveis também induzem comportamento mais partidário do parlamentar.

Se por um lado os parlamentares atuam de forma a maximizar suas chances eleitorais, do outro lado, o Executivo visa maximizar a aprovação de sua agenda. Nunes $(2011 ; 2012)$ demonstra a formação de coalizões governativas no âmbito estadual com base em acordos partidários.

Em relação a este ponto Nunes (2011) demonstra que, assim como no contexto nacional, o sistema político estadual tende a gerar governos de coalizão com base em acordos partidários. $\mathrm{O}$ autor mapeou as estratégias dos governadores para compor maiorias no interior de legislativos estaduais. A formação das coalizões varia em função do número de atores em competição, da distribuição de preferências e sua distância ideológica relativa. Analisando o cenário na ALMG, Nunes constata que mesmo que os deputados estaduais estejam atrás de pork para alocar nos seus redutos, a coordenação política é realizada pelos líderes partidários com o governador.

Nunes (2012) atenta para a natureza relacional e a complexidade da barganha que envolve deputados, partidos e o governador na construção de apoio parlamentar. Portanto, o autor vislumbra quatro estratégias de negociação que envolveria o Executivo. Duas estratégias permitem ao governador negociar com partidos e outras duas permitem negociar diretamente com os parlamentares individualmente. A primeira estratégia consiste em o Executivo negociar apoio partidário distribuindo cargos e secretarias entre partidos parceiros da coalizão (o que caracteriza a construção de coalizões na Câmara dos Deputados) ou o governador pode liberar benefícios distributivos via líderes partidários. As outras duas formas de negociação envolvem os mesmos recursos por parte do executivo, entretanto o mesmo os negocia diretamente com os deputados. 
Segundo dados coletados por pesquisa de survey ${ }^{5}$ com deputados estaduais, mais de $50 \%$ dos respondentes disseram que a melhor estratégia é a negociação de recursos via líderes partidários ou não.

Em outro artigo Nunes (2012) elenca quatro estratégias plausíveis para o governador utilizar na obtenção de apoio parlamentar. A primeira estratégia seria o governador montar uma coalizão multipartidária negociando cargos/secretárias com os partidos - tese clássica do funcionamento do presidencialismo de coalizão na Câmara dos Deputados. A segunda estratégia seria o governador negociar a liberação de pork com os partidos. A terceira opção seria a negociação de cargos diretamente com os parlamentares. A última estratégia seria a negociação direta de pork com os deputados. Os achados de Nunes $(2011$; 2012) permitem afirmar que, diferentemente do que a literatura vem sugerindo, governadores para maximizar seu apoio não precisam escolher entre priorizar pork ou cargos.

Diferentemente de Nunes, Sandes-Freitas e Massonetto $(2017)^{6}$, consideram que a construção de coalizões no estado não obedece à mesma lógica observada no plano federal. Portanto a distribuição de secretarias e cargos não obedece à proporcionalidade das cadeiras obtidas no parlamento pelos parceiros coligados nas eleições - somente aqueles com maior peso legislativo são agraciados. Os governadores tendem a premiar o seu próprio partido na distribuição das secretarias e a grande maioria dos governos são minoritários. Assim sendo, as coalizões no plano estadual funcionariam sobre a égide do "ultrapresidencialismo" sendo o governo polo de atração de parlamentares, independentemente de negociações partidárias por secretarias de estado.

Uma síntese possível entre os trabalhos de Nunes (2012) e Sandes-Freitas e Massonetto (2017) é que a obtenção de apoio à agenda do executivo nos legislativos estaduais envolve uma complexa rede de negociações que podem ou não envolver os partidos políticos e que os governadores, a depender do contexto político-partidários em seus estados, devem avaliar quais são os recursos que deverão mobilizar. Lembrando que as estratégias disponíveis para o governador não são mutuamente excludentes, podendo o mesmo distribuir cargos/benefícios individuais para alguns parlamentares de determinado partido e negociar cargos/benefícios com as lideranças partidárias de outro partido. Neste caso entender quais são as expectativas dos atores políticos em relação aos seus interesses e possibilidades de ganhos é a grande tarefa política dos governadores de estado para obterem apoio para a sua agenda. Dito de outra forma, considerar as

\footnotetext{
5 Trata-se da pesquisa "Trajetórias, perfis e padrões de interação de legisladores estaduais em doze unidades da federação". Durante os meses de setembro de 2007 a fevereiro de 2008, foi realizada a primeira rodada do survey a deputados nas assembleias legislativas da Bahia, Ceará, Goiás, Minas Gerais, Mato Grosso, Pará, Pernambuco, Rio de Janeiro, Rio Grande do Sul, Santa Catarina, São Paulo e Tocantins. Foram entrevistados 513 deputados estaduais, em um universo de 624. Em 2012 foi realizado um novo survey, sendo entrevistados 439 parlamentares. O projeto contou com o financiamento da FAPEMIG, CNPq e CAPES. Os trabalhos de Castro et. al. (2009); Melo (2011;2015), Nunes (2012) e Inácio e Amaral (2013) também se valem de dados desta pesquisa.

${ }^{6}$ Os autores estudam a formação de maiorias legislativas na Alesp e Assembleia Legislativa do Piauí (Alepi) entre 1995 a 2010.
} 
variáveis políticas é de suma importância para que alguns governadores sejam mais exitosos do que outros.

\section{2 - Índice de Poder Legislativo do Executivo (IPLE)}

O objetivo da seção é apresentar o construto do Índice de Poder Legislativo do Executivo (IPLE). Tal índice se propõe como medida alternativa para avaliar o sucesso legislativo do Executivo $^{7}$. A expectativa é que o índice seja sensível a variações nos contextos políticos observados nos estados. A construção do índice pretende lidar com duas das principais críticas aos indicadores canônicos de sucesso legislativo, a saber, o aspecto estático de um fenômeno que é processual e a possibilidade de se introduzir o próprio elemento de conflito entre os poderes.

Isto posto, a construção do índice de Poder Executivo levou em conta, portanto, duas variáveis $^{8}$. A primeira é a taxa de sucesso legislativo, ou seja, o percentual de projetos de autoria do Executivo que é aprovado, tendo em vista o número total de iniciativas apresentadas por este poder. Neste trabalho, será considerado bem-sucedido o governador que aprova um número maior ou igual a $87 \%$ de seus projetos. O patamar foi estabelecido tendo como referência de governo bem-sucedido a média de aprovação de projetos do Executivo em assembleias legislativas (TOMIO e RICCI, 2012b; TOMIO e RICCI, 2018b).

A segunda variável considerada é a capacidade de o governador manter os seus vetos. É através do veto que o Executivo consegue evitar que as iniciativas aprovadas no Legislativo se afastem de suas preferências e que seus projetos sejam preservados de alterações significativas introduzidas pelos parlamentares. Será considerado bem-sucedido o governador que mantiver pelo menos 70\% de seus vetos (SANTOS, 2001; TOMIO e RICCI, 2012b, GRAÇA, 2016).

Para o cálculo do IPLE o primeiro passo adotado foi transformar os valores percentuais em proporção. Os valores foram somados e divididos por dois. A seguir a fórmula utilizada:

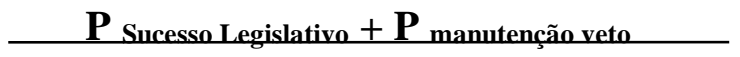

2

O índice varia de 0 a 1 , sendo que o valor 1 seria a situação em que o governador de estado obtém $100 \%$ de sucesso legislativo e manutenção de veto.

\footnotetext{
${ }^{7}$ Apesar de se pretender com o IPLE uma medida alternativa para se medir sucesso legislativo do Executivo a iniciativa não é inédita (DINIZ, 2005; NUNES, 2013).

${ }^{8}$ A despeito de ser um importante indicador do processo legislativo a Taxa de Dominância não foi considerada para o cálculo do índice. Nas Assembleias Legislativas é muito grande o percentual de legislação de baixa relevância aprovado. Este tipo de iniciativa quase sempre tem origem entre os legisladores e seu volume pode ser maior do que legislação relevante, sua contabilização acaba por subestimar em demasia a participação do Executivo.
} 


\section{3 - A Produção Legislativa nos Estados (Indicadores canônicos)}

Esta seção apresenta os dados referentes à produção legislativa. A Tabela 1 mostra o número de projetos apresentados em cada assembleia e por autoria para as legislaturas 2007/2011 e 2011/2015. No total foram 25.089 propostas legislativas somando-se todas as assembleias 9 . Destaca-se o grande ativismo na proposição de leis por parte do Poder Legislativo, responsável por propor, em média, em torno de $82 \%$ das leis, o que é condizente com o baixo custo para apresentar proposições conforme já observado por Tomio e Ricci (2012a).

Tabela 1 - Número de projetos apresentados por Assembleia e por autor (2007/2011 e 2011/2015)

\begin{tabular}{lcccc}
\hline UF**** & $\begin{array}{c}\mathbf{N}^{\mathbf{0}} \text { de Projetos } \\
\text { Apresentados *** }\end{array}$ & $\begin{array}{c}\mathbf{N}^{\mathbf{0}} \text { de Projetos } \\
\text { Apresentados } \\
\text { pelo Executivo }\end{array}$ & $\begin{array}{c}\mathbf{N}^{\mathbf{0}} \text { de Projetos } \\
\text { Apresentados pelo } \\
\text { Legislativo }\end{array}$ & $\begin{array}{c}\mathbf{N}^{\mathbf{0}} \text { de Projetos } \\
\text { Apresentados por } \\
\text { Outros }\end{array}$ \\
\hline BA1 & $2398(100)$ & $201(8,38)$ & $2167(90,37)$ & $30(1,25)$ \\
BA2 & $1167(100)$ & $291(24,93)$ & $860(73,70)$ & $16(1,37)$ \\
CE1 & $1337(100)$ & $27(2,00)$ & $1306(97,70)$ & $4(0,30)$ \\
CE2 & $950(100)$ & $56(5,89)$ & $884(93,05)$ & $8(0,84)$ \\
MG1 & $3134(100)$ & $273(8,71)$ & $2832(90,36)$ & $29(0,92)$ \\
MG2 & $2473(100)$ & $358(14,48)$ & $2083(84,23)$ & $32(1,29)$ \\
PA* & $549(100)$ & $134(24,40)$ & $402(73,22)$ & $13(2,37)$ \\
RS1 & $1554(100)$ & $692(44,53)$ & $773(49,74)$ & $89(5,73)$ \\
RS2 & $1296(100)$ & $742(57,25)$ & $480(37,04)$ & $74(5,71)$ \\
PE* & $641(100)$ & $403(62,87)$ & $215(33,54)$ & $23(3,59)$ \\
RJ** & Sem Informação & 105 & Sem Informação & Sem Informação \\
SC* & $2437(100)$ & $608(24,95)$ & $1752(71,89)$ & $77(3,16)$ \\
SP1 & $4518(100)$ & $137(3,03)$ & $4356(96,41)$ & $25(0,55)$ \\
SP2 & $2635(100)$ & $115(4,36)$ & $2498(94,80)$ & $22(0,83)$ \\
Total & $\mathbf{2 5 0 8 9 ( 1 0 0 )}$ & $\mathbf{4 0 3 7}(\mathbf{1 6 , 1 )}$ & $\mathbf{2 0 6 0 8}(\mathbf{8 2 , 1 4})$ & $\mathbf{4 4 2}(\mathbf{1 , 7 6})$
\end{tabular}

Fonte: Elaboração própria a partir do banco de dados *Legislativos Assembleias Estaduais (TOMIO e RICCI); ** Santos e Graça (2009) e; Banco de Produção Legislativa Subnacional do CEL-DCP.

***O período de produção de dados para os estados do Rio de Janeiro, Pará e Pernambuco referem-se ao primeirc biênio da legislatura 2007-2008.

**** Os números 1 e 2 à frente das siglas dos estados refere-se a legislatura considerada. O número 1 indica a legislatura 2007-2011. O número 2 a legislatura 2011-2015.

A Tabela 2 mostra o total de leis aprovadas em cada uma das assembleias analisadas e o total de leis aprovadas por iniciativa. Ao todo foram aprovadas 14.386 leis somando-se todas as casas legislativas. Deste total o Legislativo aprovou 10.482 leis, em torno de $73 \%$ e o Executivo aprovou aproximadamente $25 \%{ }^{10}$. O ativismo legislativo das Assembleias resulta em um grande número de projetos aprovados.

\footnotetext{
${ }^{9}$ Não foi possível obter todos os dados para o Rio de Janeiro.

${ }^{10}$ Aproximadamente $2 \%$ dos projetos foram aprovados por outros autores tais como Ministério Público, Tribunal de Contas e Poder Judiciário.
} 
Tabela 2 - Número de projetos aprovados por assembleia e por autor (2007/2011 e 2011/2015)

\begin{tabular}{lcccc}
\hline UF**** & $\begin{array}{c}\mathbf{N}^{\mathbf{0}} \text { de Projetos } \\
\text { Aprovados nas } \\
\text { Assembleias*** }\end{array}$ & $\begin{array}{c}\mathbf{N}^{\mathbf{0}} \text { de Projetos } \\
\text { do Executivo } \\
\text { aprovados }\end{array}$ & $\begin{array}{c}\mathbf{N}^{\mathbf{0}} \text { de Projetos do } \\
\text { Legislativo } \\
\text { aprovados }\end{array}$ & $\begin{array}{c}\mathbf{N}^{\mathbf{0}} \text { de Projetos } \\
\text { Aprovados por } \\
\text { Outros }\end{array}$ \\
\hline BA1 & 1642 & 169 & 1458 & 15 \\
BA2 & 1014 & 189 & 814 & 11 \\
CE1 & 630 & 27 & 599 & 4 \\
CE2 & 488 & 56 & 426 & 6 \\
MG1 & 1650 & 206 & 1423 & 21 \\
MG2 & 2175 & 304 & 1848 & 23 \\
PA* & 271 & 119 & 140 & 12 \\
PE* & 579 & 398 & 160 & 21 \\
RS1 & 947 & 602 & 277 & 68 \\
RS2 & 928 & 637 & 237 & 54 \\
RJ** & 397 & 86 & 295 & 16 \\
SC* & 1650 & 531 & 1047 & 72 \\
SP1 & 1059 & 128 & 914 & 17 \\
SP2 & 956 & 102 & 844 & 10 \\
Total & $\mathbf{1 4 3 8 6 ( 1 0 0 )}$ & $\mathbf{3 5 5 4}(\mathbf{2 4 , 7 0 )}$ & $\mathbf{1 0 4 8 2}(\mathbf{7 2 , 9 0})$ & $\mathbf{3 5 0}(\mathbf{2 , 4 0 )}$ \\
\hline
\end{tabular}

Fonte: Elaboração própria a partir do banco de dados *Legislativos Assembleias Estaduais (TOMIO e RICCI); ** Santos e Graça (2009) e; Banco de Produção Legislativa Subnacional do CEL-DCP.

***O período de produção de dados para os estados do Rio de Janeiro, Pará e Pernambuco referem-se ao primeiro biênio da legislatura 2007-2008.

**** Os números 1 e 2 à frente das siglas dos estados refere-se a legislatura considerada. O número 1 indica a legislatura 2007-2011. O número 2 a legislatura 2011-2015.

Contudo, a observação dos dados de forma desagregada, conforme se pode ver na Tabela 3 , evidencia uma realidade diversificada entre as assembleias o que pode denotar interações diversificadas entre os Poderes.

Tabela 3 - Número de projetos apresentados pelo Executivo, Número de Projetos Aprovados de origem do Executivo e Taxa de Sucesso Legislativo do Executivo nas Assembleias Legislativas

(2007/2011 e 2011/2015)

\begin{tabular}{lccc}
\hline UF***** & $\begin{array}{c}\mathbf{N}^{\circ} \text { de Projetos Apresentados pelo } \\
\text { Executivo*** }\end{array}$ & $\begin{array}{c}\mathbf{N}^{\circ} \text { de Projetos } \\
\text { Aprovados de origem } \\
\text { do Executivo }\end{array}$ & $\begin{array}{c}\text { Taxa de Sucesso do } \\
\text { Executivo (\%) }\end{array}$ \\
\hline BA1 & 201 & 169 & 84,08 \\
BA2 & 291 & 189 & 64,95 \\
CE1 & 27 & 27 & 100,00 \\
CE2 & 58 & 56 & 96,55 \\
MG1 & 273 & 206 & 75,46 \\
MG2 & 358 & 304 & 84,92 \\
PA* & 134 & 119 & 88,80 \\
PE* & 403 & 398 & 98,76
\end{tabular}




\begin{tabular}{llll} 
RJ** & 105 & 86 & 82,00 \\
RS1 & 692 & 602 & 87,00 \\
RS2 & 742 & 637 & 85,85 \\
SC* & 608 & 531 & 87,34 \\
SP1 & 137 & 128 & 93,43 \\
SP2 & 115 & 102 & 88,70 \\
\hline
\end{tabular}

Fonte: Elaboração própria a partir do banco de dados *Legislativos Assembleias Estaduais (TOMIO e RICCI); ** Santos e Graça (2009) e; Banco de Produção Legislativa Subnacional do CEL-DCP.

***O período de produção de dados para os estados do Rio de Janeiro, Pará e Pernambuco referem-se ao primeiro biênio da legislatura 2007-2008.

**** Os números 1 e 2 à frente das siglas dos estados refere-se a legislatura considerada. O número 1 indica a legislatura 2007-2011. O número 2 a legislatura 2011-2015.

Por fim, foi analisada a taxa de manutenção de vetos, ou seja, a capacidade de o Executivo fazer prevalecer as suas preferências na relação com o Legislativo em situações nas quais o conflito se explicita. A Tabela 4 apresenta o número de projetos vetados, o número de vetos mantidos, o número de vetos rejeitados e a taxa de manutenção" ${ }^{11}$.

Tabela 4 - Número de Vetos, Número de Vetos Mantidos, Números de Vetos Rejeitados e Taxa de Manutenção de Vetos nas Assembleias Legislativas em Projetos de Lei de Autoria do Executivo/Legislativo (2007/2011 e 2011/2015)

\begin{tabular}{lcccc}
\hline UF**** & $\begin{array}{c}\mathbf{N}^{\mathbf{0}} \text { de Projetos } \\
\text { Vetados*** }\end{array}$ & $\begin{array}{c}\mathbf{N}^{\mathbf{0}} \text { de Vetos } \\
\text { Mantidos }\end{array}$ & $\begin{array}{c}\mathbf{N}^{\mathbf{0}} \text { de Vetos } \\
\text { Rejeitados }\end{array}$ & $\begin{array}{c}\text { Taxa de } \\
\text { Manutenção(\%) }\end{array}$ \\
\hline BA1 & 2 & 2 & 0 & 100,00 \\
BA2 & 2 & 1 & 1 & 50,00 \\
CE1 & 0 & - & 0 & 100,00 \\
CE2 & 2 & 2 & 0 & 100,00 \\
MG1 & 41 & 22 & 19 & 53,66 \\
MG2 & 37 & 31 & 6 & 83,79 \\
PA* & 12 & 11 & 1 & 91,67 \\
PE* & 0 & - & - & 100,00 \\
RJ** & 23 & 19 & 4 & 82,60 \\
RS1 & 22 & 15 & 7 & 68,20 \\
RS2 & 41 & 25 & 16 & 61,00 \\
SC* & 190 & 152 & 37 & 80,00 \\
SP1 & 232 & - & 0 & 100,00 \\
SP2 & 166 & - & 0 & 100,00 \\
\hline
\end{tabular}

Fonte: Elaboração própria a partir do banco de dados *Legislativos Assembleias Estaduais (TOMIO e RICCI); ** Santos e Graça (2009) e; Banco de Produção Legislativa Subnacional do CEL-DCP.

***O período de produção de dados para os estados do Rio de Janeiro, Pará e Pernambuco referem-se ao primeiro biênio da legislatura 2007-2008.

**** Os números 1 e 2 à frente das siglas dos estados refere-se a legislatura considerada. O número 1 indica a legislatura 2007-2011. O número 2 a legislatura 2011-2015.

${ }^{11}$ O Executivo em São Paulo vetou 398 leis. Entretanto, até o final de 2014, nenhum veto havia sido apreciado pela ALESP. Todos os vetos foram apreciados na legislatura seguinte, em 2015. O resultado foi altamente favorável ao Executivo: apenas 3 vetos foram derrubados, o que representa uma taxa de manutenção de 99,25\%. 
A observação dos dados permite conclusões análogas a outras já demonstradas em outros trabalhos sobre a produção legislativa nos estados brasileiros (SANTOS, 2001; NUNES, 2008; TOMIO e RICCI, 2010; 2012a; 2012b;2018b).

\section{4 - Calibrando o Resultado de Interesse}

A primeira seção mostrou como se deu a construção do IPLE. Agora, trata-se de ver como o índice se comporta para cada uma das legislaturas estudadas. A Tabela 5 apresenta a distribuição das frequências das duas variáveis que compõe o IPLE e o valor do índice em todos os estados. A última linha traz o valor do IPLE considerando os parâmetros empíricos estipulados para se classificar um governo de sucesso. O limiar definido para se considerar um Executivo estadual poderoso é o valor de IPE de 0,785 (calibração). Este valor servirá de referência (ponto de corte) na utilização da técnica de Crisp-set/QCA. Dos quatorze casos considerados no trabalho apenas quatro apresentaram valores inferiores ao ponto de corte estabelecido.

Tabela 5 - Sucesso Legislativo do Executivo, Taxa de Manutenção de Vetos nas Assembleias Legislativas e IPLE.

\begin{tabular}{lccc}
\hline UF***** & $\begin{array}{c}\text { Sucesso Legislativo do } \\
\text { Executivo (\%) }\end{array}$ & $\begin{array}{c}\text { Taxa de Manutenção } \\
\text { de Veto } *\end{array}$ & IPLE (y) \\
\hline BA2 & 64,95 & 50,00 & 0,575 \\
MG1 & 75,46 & 53,66 & 0,646 \\
MG2 & 84,92 & 83,79 & 0,843 \\
RJ** & 82,00 & 82,60 & 0,823 \\
RS2 & 85,85 & 61,00 & 0,734 \\
SC* & 87,34 & 80,00 & 0,837 \\
BA1 & 84,08 & 100 & 0,920 \\
RS1 & 87,00 & 68,20 & 0,776 \\
SP2 & 88,70 & 100 & 0,943 \\
SP1 & 93,43 & 100 & 0,967 \\
CE1 & 100 & 100 & 1 \\
CE2 & 96,55 & 100 & 0,983 \\
PA* & 88,80 & 91,67 & 0,902 \\
PE* & 98,76 & 100 & 0,994 \\
Parâmetro & $\mathbf{8 7 , 0 0}$ & $\mathbf{7 0 , 0 0}$ & $\mathbf{0 , 7 8 5}$ \\
\hline
\end{tabular}

Fonte: Elaboração própria a partir do banco de dados *Legislativos Assembleias Estaduais (TOMIO e RICCI); ** Santos e Graça (2009) e; Banco de Produção Legislativa Subnacional do CEL-DCP.

***O período de produção de dados para os estados do Rio de Janeiro, Pará e Pernambuco referem-se ao primeiro biênio da legislatura 2007-2008.

**** Os números 1 e 2 à frente das siglas dos estados refere-se a legislatura considerada. O número 1 indica a legislatura 2007-2011. O número 2 a legislatura 2011-2015. 


\section{1 - A natureza política do sucesso do Executivo. Calibração das Condições Causais}

Quais fatores políticos explicam a variação do IPLE? As variáveis políticas a serem consideradas neste trabalho serão o percentual de parlamentares que se colocam na oposição ao governador, a fragmentação partidária e a polarização ideológica. Teoricamente é de se esperar que os custos de transação para se aprovar a agenda do Executivo aumentem quando o governador enfrente um maior contingente de parlamentares da oposição e em parlamentos muito fragmentados e polarizados, logo, espera-se que: 1) governadores que encontrem uma oposição menos numerosa terão menores dificuldades na condução de sua agenda de governo, tendo reflexos sobre IPLE. 2) Expectativa semelhante se tem quando os governadores operam em assembleias legislativas que contam com menor número de partidos relevantes e 3) assembleias legislativas menos polarizadas propiciam um ambiente favorável para os governadores obterem sucesso legislativo.

\section{Tamanho da Oposição}

A primeira condição causal a ser calibrada será o tamanho da oposição nas assembleias. Foi estabelecido o limiar de 33,4\% como ponto de corte. Tal valor corresponde a um terço dos deputados e ao quórum necessário para que se instaure uma Comissão Parlamentar de Inquérito (CPI). Assembleias que apresentam valores $\leq 33,4 \%$ não possuem um contigente expressivo de parlamentares na oposição. O Gráfico 1 apresenta o percentual de deputados que se consideram oposição ao Executivo nos quatorze casos analisados. Pode-se observar que apenas dois governadores enfrentaram um cenário em que a oposição era numerosa na assembleia. Ambos os casos foram registrados no Rio Grande do Sul. 
Gráfico 1 - Percentual de Deputados Estaduais que se consideram oposição (ponderado SP2)*

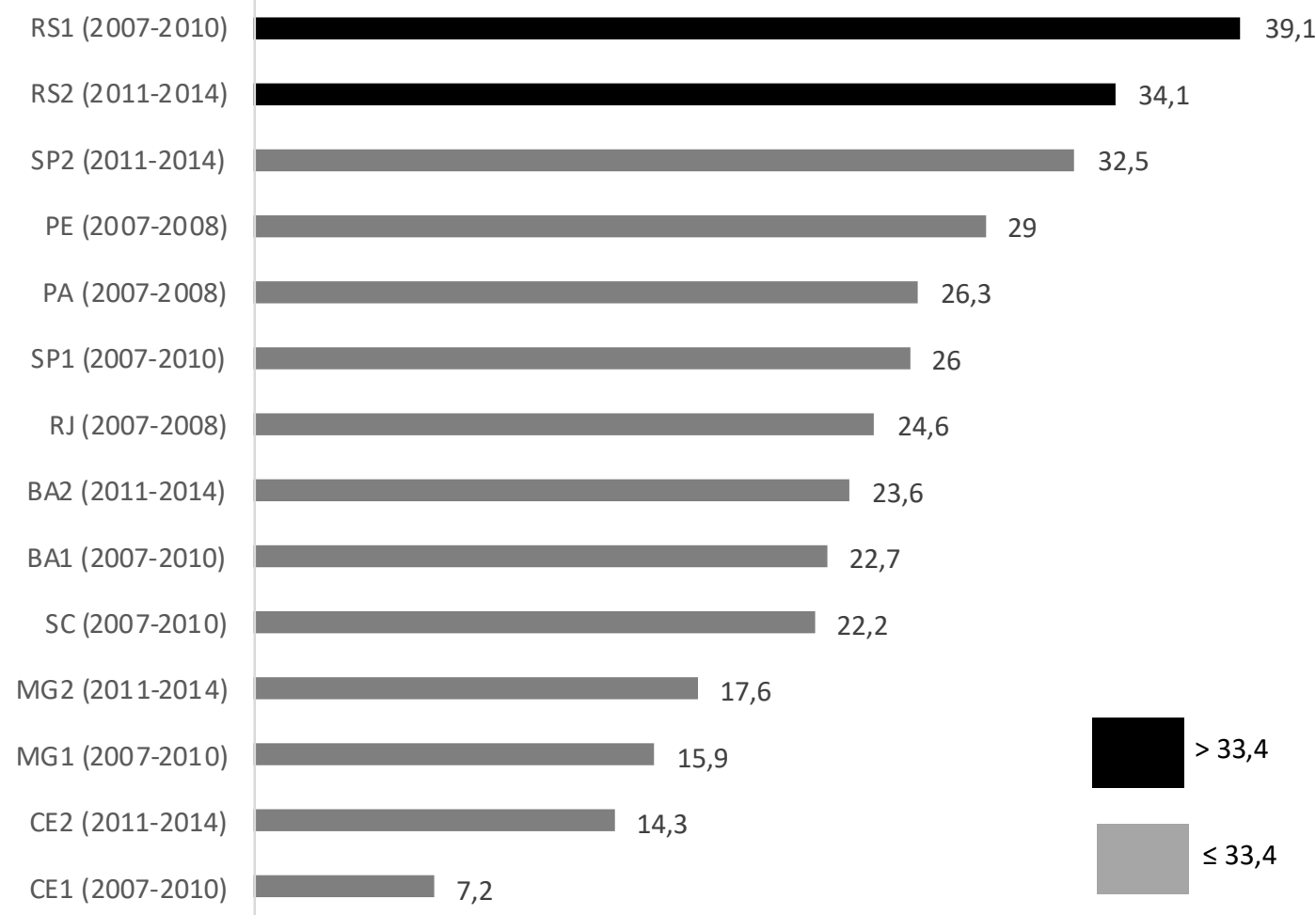

Fonte: Elaboração própria a partir de dados da pesquisa "Trajetórias, perfis e padrões de interação de legisladores estaduais em doze unidades da Federação" do Centro de Estudos Legislativos do DCP-UFMG.

*Os dados para São Paulo em 2012 (SP2) estavam subestimados para alguns partidos. Foi feita uma imputação à partir da distribuição da frequência real dos partidos com representação na Assembleia Legislativa de São Paulo. Constatouse que as respostas ao questionário iam na mesma direção e assim se atribui o mesmo valor. Quando havia conflito entre o padrão de resposta e frequência metade era distribuída como oposição e metade como governo.

\section{Fragmentação legislativa (número efetivo de partidos parlamentares)}

A fragmentação das assembleias foi operacionalizada através do Número Efetivo de Partidos (NEP), sendo $(\mathrm{N})=1 / \mathrm{HH}$.

Na ausência de parâmetros empíricos fornecidos pela literatura ${ }^{12}$, optou-se por se arbitrar um limiar empírico a partir dos próprios dados. Para tanto calculou-se a média ponderada do NEP, sendo o fator de ponderação o número de cadeiras de cada uma das assembleias analisadas neste trabalho, conforme pode-se ver na fórmula abaixo:

$$
\bar{x}=\frac{\sum \text { Nep }_{\mathrm{i}} * \mathrm{n}^{\mathrm{o}} \text { de } \text { cadeiras }_{\mathrm{i}}}{\sum \mathrm{n}^{\mathrm{o}} \text { de cadeiras }} \mathrm{i}
$$

\footnotetext{
12 Mainwaring e Scully (1995) classificam os sistemas de partido a partir NEP. Pela classificação elaborada pelos autores quando o NEP é inferior a 1,7 temos um sistema de partido predominante; quando o valor se encontra entre 1,8 e 2,4 temos o sistema de "dois partidos e meio"; valores entre 2,5 e 3,9 conformam sistemas de pluralismo moderado e; sistemas que apresentem o valor do NEP igual ou maior de 4 é um sistema pluralista extremo.Tal classificação não permite que se estabeleça qualquer diferenciação entre os estados brasileiros.
} 
Onde, “i” são n assembléias possíveis, no caso em questão são os valores dos 9 casos considerados no trabalho.

Assembleias que obtiveram o valor do NEP $\geq 8,45$ (maior ou igual) encontram-se no conjunto das assembleias fragmentadas.

Gráfico 2 - NEP para os estados considerando o limiar (2006 e 2010)

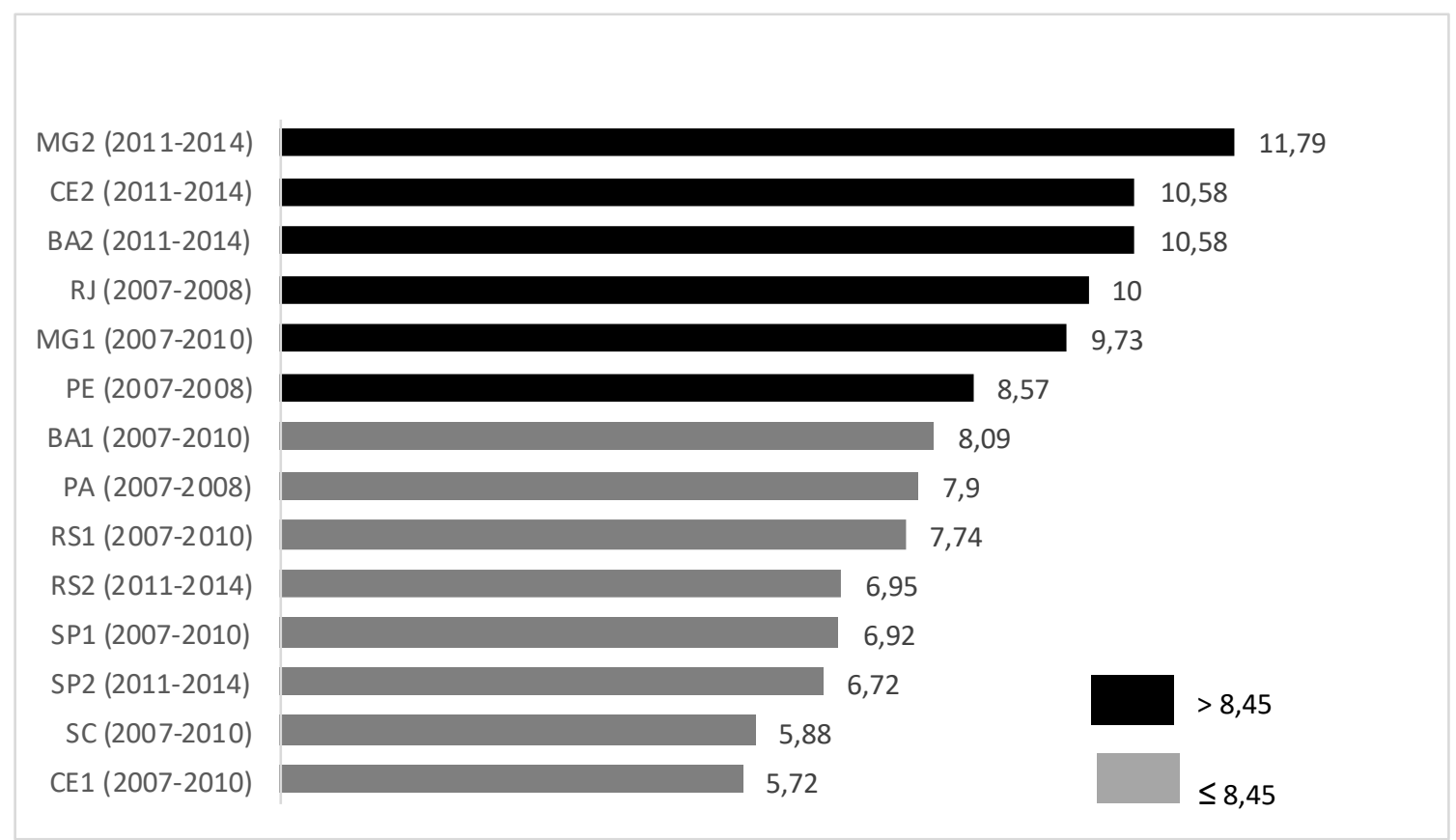

Fonte: Elaboração própria a partir dos dados do Tribunal Superior Eleitoral e Banco de Dados Eleitorais (NICOLAU).

\section{Polarização Ideológica}

Além do contingente de oposição parlamentar ao Executivo e da fragmentação partidária observada nas assembleias, a distância ideológica entre os partidos com representação na assembleia pode configurar uma condição causal que afeta o resultado de interesse há uma relação inversamente proporcional entre polarização e a relação entre os poderes (MAINWARING e SCULLY 1995 apud SANTOS et. al., 2014). Foi utilizado o índice de Polarização Ideológica Ponderada (IPP) ${ }^{13}$, que considera o peso parlamentar dos partidos, uma vez que a proporção de cadeiras de um partido e seu posicionamento na escala ideológica compõe o índice, conforme se pode ver abaixo:

$$
I P P=\sum p_{i}\left(\mathbf{x}_{\mathbf{i}}-\Sigma \mathbf{p}_{\mathbf{i}} \mathbf{x}_{\mathbf{i}}\right)^{2}
$$

onde pi é a proporção de cadeiras de um partido (i) e xi o posicionamento de um dado partido (i) em uma escala esquerda direita onde 1 significa esquerda e 10 direita.

\footnotetext{
13 Outra forma de se medir polarização é o Índice de polarização. IP $=(x d-x e) / 9$, onde xd é o partido com a identificação ideológica mais extrema à direita, e xe é o partido com identificação ideológica mais extrema à esquerda. (SARTORI e SANI, 1992 apud MONTERO e SÀEZ, 2009).
} 
Com base em Santos et. al. (2014) vamos utilizar o valor médio do IPP, calculado considerando todas as assembleias, para definir o ponto de corte. $\mathrm{O}$ valor médio observado foi de 2,2. Assim sendo assembleias que apresentam valores maiores que 2,2 pertencem ao conjunto de assembleias polarizadas.

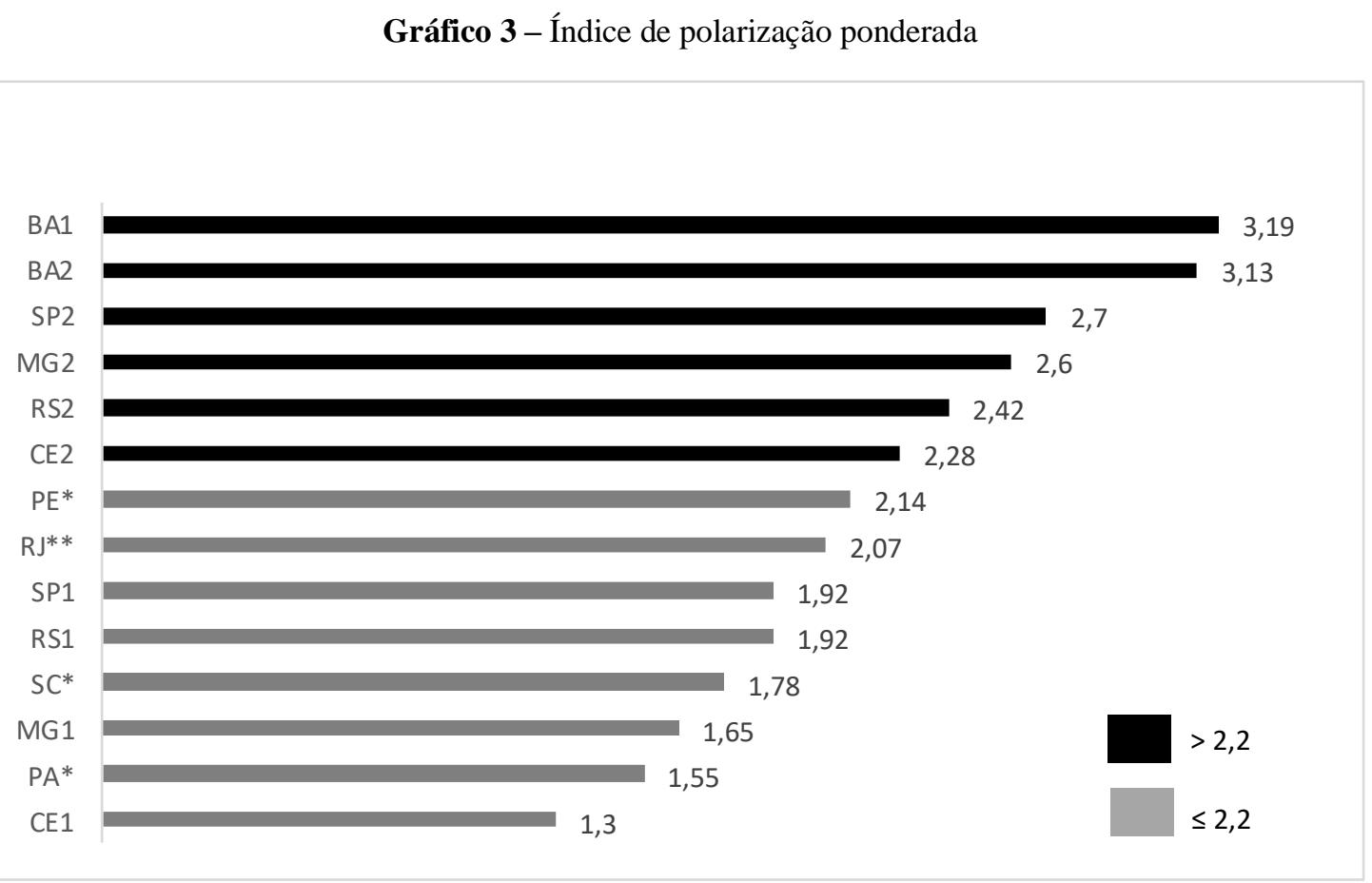

Fonte: Elaboração própria a partir de dados da pesquisa "Trajetórias, perfis e padrões de interação de legisladores estaduais em doze unidades da federação".

Concluída a calibragem do resultado de interesse (IPLE) e das três condições causais a próxima seção trata de resumir a matriz analítica e empreender a análise de resultados.

\section{5 - Análises dos Dados}

Um dos aspectos relacionados à complexidade do objeto em Ciência Política refere-se à natureza multicausal dos fenômenos sociais. A Qualitative Comparative Analyses (QCA) ${ }^{14}$ se apresenta como uma alternativa analítica para lidar com o problema de desenhos de pesquisa com poucos casos e com modelos explicativos multicausais (PÉREZ-LIÑAN, 2010; SANTOS et. al., 2014; SANDES FREITAS e BIZARRO NETO, 2015). A QCA é uma abordagem orientada para o estudo de casos que combina elementos da análise quantitativa e qualitativa por ser uma técnica orientada por variáveis e para casos respectivamente (BERG-SCHLOSSER et. al., 2009;

\footnotetext{
${ }^{14}$ Técnica inicialmente desenvolvida por Ragin (1987). Existem três técnicas de QCA a saber: 1) crisp-set QCA (csQCA) baseada em lógica binária booleana; 2) Fuzzy-set QCA (fsQCA) que atribiu valores entre 0 e 1 e; 3 ) multivalue QCA (mvQCA) onde as condições podem assumir mais de duas categorais $(0,1,2 \mathrm{e} 3$, por exemplo). A técnica utilizada neste artigo é a Crisp-Set.
} 
WAGEMANN, 2012).

A QCA visa verificar relações de causalidade, vinculando condições causais a um determinado resultado de interesse, caracterizando-se como um poderoso instrumento de inferência causal na análise cruzada de dados (WAGEMANN, 2012). Dessa forma, a técnica "permite analizar sistemáticamente todas las combinaciones posibles de condiciones causales con el fin de identificar mecanismos de causalidad coyuntural, es decir, configuraciones de factores que resultan suficientes para producir el resultado de interés". (SANTOS, et. al., 2014).

Onde $\mathrm{Y}$ representa o fenômeno de interesse, que conforme a equação é função da combinação de múltiplas condições causais $\left(\mathrm{X}_{1}, \mathrm{X}_{2}, \mathrm{X}_{3} \ldots \mathrm{X}_{\mathrm{n}}\right)$. Para o caso em análise, $\mathrm{Y}$ representa o sucesso/insucesso do legislativo medido através do IPLE. $\mathrm{X}_{1}$ é o contingente de parlamentares da oposição, $X_{2}$ é fragmentação da assembleia e $X_{3}$ é a distância ideológica verificada entre os partidos presentes na Assembleia. Desta forma, o modelo de análise é expresso da seguinte maneira:

\section{$Y_{\text {Sucesso Legislativo (IPLE) }}=f\left(\mathbf{x}_{\text {oposição }}+\mathbf{X}_{\text {fragmentação }}+\mathbf{X}_{\text {polarização }}\right)$}

Para se empreender uma análise QCA é necessário seguir um protocolo comparativo estabelecido por Charles Ragin para se verificar quais as configurações causais impactam o resultado de interesse (PÉREZ-LIÑAN, 2010:138) ${ }^{15}$. Passo a ser dado na próxima subseção.

\section{1 - Matriz de Dados}

A Tabela 7 apresenta a Matriz de Dados. Trata-se de uma Tabela onde se verifica a ocorrência ou não do resultado de interesse (y) e das condições causais $\left(\mathrm{x}_{1}, \mathrm{x}_{2}, \mathrm{x}_{3} \ldots \mathrm{x}_{\mathrm{n}}\right)$, através de uma codificação binária, onde 0 (zero) significa não ocorrência e 1 (um) ocorrência. A primeira coluna apresenta os casos. Na segunda é possível observar a ocorrência ou não do resultado de interesse (y). Nas três colunas seguintes é possível observar a ocorrência ou não de $x_{1}$ (Oposição), $\mathrm{x}_{2}$ (Fragmentação) e $\mathrm{x}_{3}$ (Polarização), considerando a calibragem de todas as variáveis.

\footnotetext{
${ }^{15} \mathrm{O}$ protocolo envolve quatro fases analíticas, a saber: 1) Construção da Tabela Comparativa que tem como objetivo organizar a informação qualitativa e auxiliar na identificação de possíveis condições necessárias; 2) Articular a teoria tipológica através da construção da Tabela de Verdade e identificar as configurações causais suficientes; 3) exame das configurações para as quais não há exemplos históricos e; 4) redução do número de configurações suficientes através de um processo de minimização lógica, a fim de se obter os implicantes primários. (RAGIN, 2008; RIHOUX e RAGIN, 2009 apud PÉREZ-LIÑAN, 2010:138).
} 
Tabela 6 - Matriz de Dados

\begin{tabular}{|c|c|c|c|c|}
\hline UF & $\begin{array}{l}\text { Resultado de } \\
\text { Interesse (y) }\end{array}$ & Oposição (x1) & Fragmentação (xz) & Polarizado (x3) \\
\hline BA1 & 1 & 0 & 0 & 1 \\
\hline BA2 & 0 & 0 & 1 & 1 \\
\hline CE1 & 1 & 0 & 0 & 0 \\
\hline CE2 & 1 & 0 & 1 & 1 \\
\hline MG1 & 0 & 0 & 1 & 0 \\
\hline MG2 & 1 & 0 & 1 & 1 \\
\hline PA* & 1 & 0 & 0 & 0 \\
\hline $\mathbf{P E}^{*}$ & 1 & 0 & 1 & 0 \\
\hline $\mathbf{R} \mathbf{J}^{* *}$ & 1 & 0 & 1 & 0 \\
\hline RS1 & 0 & 1 & 0 & 0 \\
\hline RS2 & 0 & 1 & 0 & 1 \\
\hline $\mathrm{SC}^{*}$ & 1 & 0 & 0 & 0 \\
\hline SP1 & 1 & 0 & 0 & 0 \\
\hline SP2 & 1 & 0 & 0 & 1 \\
\hline
\end{tabular}

Fonte: Elaboração Própria

A construção da Matriz de Dados é passo fundamental para na identificação de condições necessárias. A técnica QCA permite a avaliação da necessidade e da suficiência de condições causais para ocorrência de um resultado, comparando número de casos sistemáticos e ao mesmo tempo reconhecendo a complexidade dentro dos casos especifícos (RIHOUX e RAGIN, 2009; WAGEMANN, 2012; DEVERS et. al, 2013 ). Desta forma, é possível identificar regularidades dentro de um subconjunto de condições e avaliar o pertencimento ou não de um caso a um resultado de interesse (conjunto) e até mesmo o grau de pertencimento do caso a um conjunto ${ }^{16}$.

\section{2 - Análise de Condições Necessárias}

Para se verificar se uma condição é necessária para a ocorrência de um resultado de interesse aplica-se o método denominado de similitude por John Stuart Mill. Para tanto os casos escolhidos devem coincidir em seu resultado. A aplicação do método se dá em dois passos. Primeiramente só se consideram os resultados positivos, ou seja, seleciona-se aqueles cujo resultado de interesse é igual a 1. Posteriormente deve-se identificar se há alguma condição causal (x) que seja comum a todos os casos. Nas palavras de Pérez-Liñan (2010:139): "La regla para identificar necesidad es simple: si $X$ es condición necesaria para $Y$, todas las instancias de Y deben mostrar la presencia de X.” (grifo do autor). Se Y então X (Y=>X). Assim, a ausência

\footnotetext{
16 A partir da teoria dos conjuntos, a técnica Crisp/QCA possibilita verificar pertencimento de uma variável a um conjunto, através do estabelcimento de variáveis dicotômicas de pertencimento (1) e não pertencimento (0).
} 
de oposição é uma condição necessária para a ocorrência do resultado de interesse, conforme análise da Tabela. Ou seja, para todo $\mathrm{Y}$ foi observado a ausência de $\mathrm{X}_{1}$, com uma cobertura de 83\%. Dos doze casos nos quais a oposição é fraca $\left(\mathrm{X}_{1}=0\right)$, dez apresentaram o resultado de interesse. Além disso, a consistência para a configuração é igual a 1. Todos os casos que apresentam o resultado de interesse $(Y=1)$ apresentam a condição de interesse.

Tabela 7 - Matriz de Dados (y=1)

\begin{tabular}{lcccc}
\hline UF & $\begin{array}{c}\text { Resultado de } \\
\text { Interesse (y) }\end{array}$ & Oposição (x1) & Fragmentação (x2) & Polarizado (x3) \\
\hline BA1 & 1 & 0 & 0 & 1 \\
CE1 & 1 & 0 & 0 & 0 \\
CE2 & 1 & 0 & 1 & 1 \\
MG2 & 1 & 0 & 1 & 1 \\
PA* & 1 & 0 & 0 & 0 \\
PE* & 1 & 0 & 1 & 0 \\
RJ** & 1 & 0 & 1 & 0 \\
SC* & 1 & 0 & 0 & 0 \\
SP1 & 1 & 0 & 0 & 0 \\
SP2 & 1 & 0 & 0 & 1
\end{tabular}

Fonte: Elaboração Própria

\section{3 - Análise de Condições Suficientes (Articulação da Teoria Tipológica)}

A análise de condições suficientes permite determinar configurações causais, uma vez que se verifica quais são as combinações e interações possíveis das diversas condições causais (x) consideradas no estudo para a ocorrência do resultado de interesse (y). (PÉREZ-LIÑAN, 2010). Para se empreender a análise de condições suficientes é necessário articular a Teoria Tipológica, através da elaboração da Tabela da Verdade e tecer uma análise sistemática de situações definidas pelas condições causais consideradas na análise.

Segundo Pérez-Liñan (2010:140) "la regla para identificar suficiencia invierte así el criterio de necesidad: si la configuración causal $X$ es condición suficiente para $Y$, todas las instancias de $\mathrm{X}$ deben ofrecer también la presencia de $\mathbf{Y}$. (grifo do autor). Desta forma é possível a ocorrência de y na ausência de x em função da existência de outras explicações causais plausíveis.

O número de configurações causais possíveis é dado pela fórmula $\mathrm{k}^{\mathrm{j}}$, onde $\mathrm{K}$ são os valores possíveis para cada uma das condições causais e $\mathrm{J}$ é o número de condições causais mobilizadas no modelo. Portanto, há oito configurações causais logicamente possíveis, uma vez que $\mathrm{k}^{\mathrm{j}}=2^{3}$.

Destaca-se a nona coluna da Tabela expõe a consistência de cada uma das configurações 
causais. A consistência é a proporção de casos positivos em uma dada configuração causal. Consistência expressa o grau em que a evidência empírica suporta a alegação de que uma relação de conjunto existe (RIHOUX; RAGIN, 2009). A consistência é calculada por $\left({ }^{\mathrm{Ny}} / \mathrm{N}\right)$. A análise deste indicador permite verificar se uma dada configuração causal é suficiente, uma vez que a literatura adota como valor de referência o valor de consistência acima de 0,8 (RAGIN, 2006).

Tabela 8 - Tabela Verdade Y= IPE

\begin{tabular}{|c|c|c|c|c|c|c|c|c|c|}
\hline Configuração & $\overline{\mathbf{X}_{1}}$ & $\overline{\mathbf{X}_{2}}$ & $\mathbf{X}_{3}$ & $\mathbf{Y}=\mathbf{0}$ & $Y=1$ & $\mathbf{N}$ & $\mathbf{N _ { \mathbf { y } }}$ & Consistência $\left({ }^{\mathrm{Ny}} / \mathrm{N}\right)$ & Resposta $^{17}$ \\
\hline 1 & $\mathbf{0}$ & $\mathbf{0}$ & $\mathbf{0}$ & & $\begin{array}{c}\text { SC; } \\
\text { SP1, } \\
\text { CE1, } \\
\text { PA }\end{array}$ & 4 & 4 & 1,00 & {$[\mathrm{~V}]$} \\
\hline 2 & $\mathbf{0}$ & $\mathbf{0}$ & 1 & & $\begin{array}{c}\text { BA1; } \\
\text { SP2 }\end{array}$ & 2 & 2 & 1,00 & {$[\mathbf{V}]$} \\
\hline 3 & 0 & 1 & 1 & BA2 & $\begin{array}{c}\text { MG2; } \\
\text { CE2 }\end{array}$ & 3 & 2 & 0,67 & {$[\mathrm{C}]$} \\
\hline 4 & 0 & 1 & 0 & MG1 & $\mathrm{RJ} ; \mathrm{PE}$ & 3 & 2 & 0,67 & {$[\mathrm{C}]$} \\
\hline 5 & 1 & 0 & 0 & $\mathrm{RS} 1$ & & 1 & 0 & 0 & {$[\mathrm{~F}]$} \\
\hline 6 & 1 & 0 & 1 & $\mathrm{RS} 2$ & & 1 & 0 & 0 & {$[\mathrm{~F}]$} \\
\hline 7 & 1 & 1 & 0 & - & - & - & - & - & [?] \\
\hline 8 & 1 & 1 & 1 & - & - & - & - & - & {$[?]$} \\
\hline
\end{tabular}

Fonte: Elaboração Própria.

Podemos observar na Tabela 9 duas configurações que apresentam o resultado de interesse, ou seja, são suficientes [V]. Tratam-se das configurações 1 e 2. Estas configurações são representadas pelas respectivas expressões booleanas:

$$
\text { Configuração 1: } \sim \mathrm{X}_{1} * \sim \mathrm{X}_{2} * \sim \mathrm{X}_{3}=>\mathrm{Y}
$$

$\&$

Configuração 2: $\sim \mathrm{X}_{1} * \sim \mathrm{X}_{2} * \mathrm{X}_{3} \Rightarrow \mathrm{Y}$

A configuração 1 mostra que a ausência de oposição e ausência de um parlamento

\footnotetext{
${ }^{17}$ Quando uma configuração apresenta o resultado de interesse ela é chamada de verdadeira [V]. Configurações que não apresentam o resultado de interesse são consideradas falsas [F]. Algumas configurações podem apresentar, ao mesmo tempo, a presença e ausência do resultado de interesse. Estas configurações são contraditórias [C], apresentam valores de consistência inferiores a 0,8. É possível ainda ter configurações para as quais não há exemplos históricos. Estas configurações são chamadas de resíduos ou remanescentes [?].
} 
fragmentado e polarizado permitem ao Executivo obter o resultado de interesse. A configuração 2 mostra que governadores serão exitosos em um contexto em que haja ausência de oposição e ausência de fragmentação mesmo diante de um parlamento polarizado ideologicamente. As configurações 5 e 6 não apresentaram o resultado de interesse, portanto são consideradas falsas $[\mathrm{F}]$.

Por fim, cabe mostrar os casos considerados contraditórios [C]. Estes podem ser observados nas configurações 3 e 4 . Uma configuração é considerada contraditória quando a configuração permite observar a ocorrência e a não ocorrência do resultado de interesse. Os valores apresentados para o índice de consistência foi de 0,67 em ambas as configurações. No total, foram seis casos sendo que em quatro destes foi obtido o resultado de interesse. A configuração 3 apresenta a seguinte combinação de condições causais, ausência de oposição em uma assembleia fragmentada e polarizada. O resultado de interesse foi observado no mandato de Antônio Anastasia em Minas Gerais (MG2) e no segundo mandato de Cid Gomes (PSB) no Ceará (CE2) e não foi observado no segundo mandato de Jacques Wagner (PT). Para a configuração 4 também se observou dois resultados de interesse e um não resultado. Tanto Sérgio Cabral (PMDB) no Rio de Janeiro e Eduardo Campos (PSB) em Pernambuco obtiveram êxito legislativo. Já Aécio Neves (PSDB) em seu segundo mandato obteve score do IPLE abaixo do parâmetro. O contexto informado pela configuração 4 é o de ausência de oposição, parlamento fragmentado e não polarizado.

Pode-se conjecturar que o fato de governadores estarem em primeiro mandato tenha contribuído para que os mesmos obtivessem sucesso na condução de sua agenda, uma vez que a possibilidade futura de reeleição torna o Executivo um polo de atração de apoio, devido a capacidade do mesmo distribuir cargos e pork no longo prazo. Estes cenários foram observados em todos os estados onde se obteve o resultado de interesse nas configurações 3 e 4 , com exceção do Ceará onde governador obteve êxito também no segundo mandato. Atenção especial será dedicada à análise dos chamados remanescentes lógicos ou contrafactuais. Passo a ser dado na próxima subseção.

\section{4 - Justificativa para o tratamento dos contrafactuais ${ }^{18}$.}

Ao se observar a Tabela da Verdade, percebe-se que as configurações 7 e 8 não apresentam nenhum caso empírico. Dito de outra forma, para uma dada configuração causal, determinada pela articulação da teoria tipológica, os casos estudados não configuram nenhum exemplo. Estas configurações são chamadas de contrafactuais ou remanescentes lógicos e estão

\footnotetext{
${ }^{18}$ A análise empreendida na subseção anterior diz respeito à solução parcimoniosa. Esta "reduz a complexidade ao mínimo considerando que: (a) as variáveis são independentes; (b) a ausência de uma variável não pode contribuir para o resultado positivo; e que (c) o resultado das configurações não verificadas não importa, ou seja, pode ser positivo ou negativo" (GURGEL e VASCONCELOS, 2012: 596).
} 
representados abaixo:

$$
\begin{aligned}
& \text { Configuração 7: } \mathrm{X}_{1} * \mathrm{X}_{2} * \sim \mathrm{X}_{3}=>[?] \\
& \text { Configuração 8: } \mathrm{X}_{1} * \mathrm{X}_{2} * \mathrm{X}_{3}=>\text { [?] }
\end{aligned}
$$

A configuração causal expressa pela configuração 7 trata de um cenário em que a oposição é mais forte e o parlamento fragmentado, mas não polarizado e a configuração 8 referese a um contexto em que há um contingente expressivo da oposição no parlamento, que por sua vez é fragmentado e polarizado.

$\mathrm{O}$ fato de não haver exemplos históricos para uma dada configuração não exime o pesquisador de tentar fazer alguma inferência para a mesma, uma vez que a análise dos remanescentes lógicos "es un componente integral del análisis configurativo de condiciones suficientes" (RAGGIN e SONNETT, 2004 apud PÉREZ-LIÑAN, 2010: 142-143).

Portanto, cabe ao pesquisador tratar estes "resíduos". Pérez-Liñan (2010:143) apresenta quatro possibilidades. A primeira possibilidade é incluir mais casos a partir da observação de fontes primárias afim de preencher a lacuna empírica. A segunda também visa preencher tal lacuna a partir da consulta a fontes secundárias para se verificar a ocorrência de casos similares ao longo da história que possam ser representativos de uma dada configuração causal. Entretanto, muitas vezes devido ao ineditismo do trabalho, tratamento de variáveis e acesso a fontes primárias e secundárias estas possibilidades não estão dadas. A terceira possibilidade de natureza teórica permite ao pesquisador imputar aos casos sem exemplo histórico valores baseados em inferências realizadas a partir dos dados disponíveis. Sendo assim, pode-se tratar todos os remanescentes como verdadeiros ou todos como falsos. Para tanto ele deve basear esta decisão na observação das configurações causais suficientes. A quarta possibilidade de natureza empírica é tratar algumas configurações remanescentes como falsas e outras como verdadeiras e explorar as conclusões a partir de tal observação. Segundo Pérez-Liñan isto permite analisar sistematicamente o que ocorre com as nossas conclusões teóricas quando se altera os supostos sobre situações históricas não observadas.

As duas primeiras possibilidades não estavam ao alcance do pesquisador, pelas limitações já mencionadas anteriormente. Desta forma, optou-se em tratar os resíduos de maneira empírica testando-os como falsos, técnica conhecida como análise da solução complexa. "A solução complexa pouco reduz as variáveis. Considera que: (a) a ausência de uma variável pode contribuir para o resultado positivo; e que: (b) todas as configurações possíveis não verificadas na amostra não geram resultados positivos" (GURGEL e VASCONCELOS, 2012: 596).

Também se testou a solução intermediária. Esta "é gerada a partir da verificação dos pares configuracionais das variáveis encontradas pela solução parcimoniosa, pressupondo multifinalidade" (GURGEL e VASCONCELOS, 2012:596), ou seja, atribuindo valores 
aleatórios de falso (0) ou verdadeiro (1) para o resultado de interesse dos remanescentes lógicos.

A análise dos remanescentes lógicos considerando a solução complexa e a intermediária reforçam os achados da solução parcimoniosa. Desta forma, este trabalho assume os remanescentes lógicos como falsos $[\mathrm{F}]$, uma vez que ao se verificar o resultado de interesse $(\mathrm{y}=1)$ na solução parcimoniosa, as condições causais $x_{1}$ (oposição) e $x_{2}$ (fragmentação) não estavam presentes nas configurações causais.

\section{5 - Minimização Lógica ou reduzindo a complexidade}

A técnica permite determinar e priorizar "condições de ocorrência". Dadas as configurações causais suficientes para explicar o resultado de interesse é possível ao pesquisador proceder a um processo de redução da complexidade. Processo este conhecido como minimização lógica e assim definir os implicantes primários para que o resultado de interesse ocorra (BERGSCHLOSSER et. Al., 2009; PÉREZ-LIÑAN, 2010).

Percebe-se que a única condição causal que difere nas configurações é a ausência de um parlamento polarizado na configuração 1 e a presença de um parlamento polarizado na configuração 2. Desta forma, procedendo ao processo de minimização lógica tem-se que o resultado de interesse ocorrerá independentemente da presença ou não de $\mathrm{x}_{3}$ (polarização) se a ausência de $\mathrm{x}_{1}$ (oposição) e ausência de $\mathrm{x}_{2}$ (fragmentação) estiverem presentes:

$$
\begin{aligned}
\text { Configuração 1: } & \sim \mathrm{X}_{1} * \sim \mathrm{X}_{2} *-\mathrm{X}_{3} \\
\& & \\
\text { Configuração 2: } & \sim \mathrm{X}_{1} * \sim \mathrm{X}_{2} * \mathrm{X}_{3} \\
& \sim \mathrm{X}_{1} * \sim \mathrm{X}_{2}
\end{aligned}
$$

Logo, a expressão booleana revela dois implicantes primários:

$$
\text { oposição * fragmentação }=>\text { Sucesso Legislativo }(\text { IPLE) }
$$

Concluindo, os governadores podem vir a ter sucesso legislativo quando operam em Assembleias Legislativas que não contem com contingente de oposição maior que 33,4\% e que não sejam fragmentadas, segundo o parâmetro estabelecido.

\section{6 - Cobertura do modelo}

A capacidade explicativa do modelo de QCA é dada pelo índice de cobertura, uma vez que ela expressa o quanto a solução minimizada cobre os casos observados (RIHOUX e RAGIN, 2009). Primeiramente se calcula a cobertura de cada configuração verdadeira [V] e posteriormente se verifica a cobertura da solução minimizada. A fórmula do cálculo da cobertura é a que segue:

$$
\text { Cobertura }=\mathbf{N}_{\mathbf{y}} / \Sigma_{\mathbf{Y}=1}
$$

onde: y é o número de casos com resultado de interesse.

A configuração 1 apresentou quatro casos que apresentam o resultado de interesse em um 
total de 10 casos. Assim sendo, a cobertura da configuração 1 é de 0,40 . A configuração 2 apresentou dois casos em 10, sendo a cobertura da configuração causal igual a 0,20. Ao considerar os implicantes primários resultantes do processo de minimização lógica temos uma cobertura de $0,6(60 \%)$.

\section{Considerações Finais}

A melhor palavra que define a produção legislativa nos estados brasileiros é diversidade. O exame do processo decisório mostra grande variação - no tempo e no espaço - que não se explica por aspectos constitucionais como já foi demonstrado por Tomio e Ricci (2010). Este artigo lidou com a explicação que mobiliza variáveis de natureza política para explicar tal variação. Para tanto, foi utilizada uma medida alternativa para se mensurar o Sucesso Legislativo do Executivo, o IPLE. A expectativa assumida era de que o indicador variasse em função das variáveis políticas tamanho da oposição, fragmentação e polarização ideológica das assembleias. A técnica de análise QCA foi mobilizada para verificar a sensibilidade do IPLE a variações nos contextos políticos. Através de análise das condições necessárias observou-se que os governadores de estado terão sucesso legislativo quando as assembleias não apresentam uma oposição numericamente forte, uma vez que sempre que o governador obteve sucesso a condição ausência da oposição se fez presente.

A análise de suficiência mostrou que das oito configurações causais possíveis quatro apresentaram o resultado de interesse, sendo que duas configurações se mostrarem verdadeiras e outras duas contraditórias. A primeira configuração verdadeira apresenta um cenário de assembleia com ausência de oposição forte, ausência de fragmentação e ausência de polarização ideológica. A segunda configuração conforma assembleias que apresentam ausência de oposição forte, ausência de fragmentação e são polarizadas. O processo de minimização lógica revelou dois implicantes primários: ausência de oposição forte e ausência de fragmentação presentes em seis casos, obtendo-se, portanto, uma cobertura de $60 \%$. Contudo, é necessário que pesquisas futuras incorporem outras variáveis - políticas e/ou institucionais - no intuito de melhorar o ajuste do modelo - afinal a QCA pressupõe a interação entre as condições causais.

\section{Referências Bibliográficas:}

ABRUCIO, Fernando Luiz. Os barões da federação: os governadores e a redemocratização brasileira. São Paulo: Hucitec/DCP-USP. 1998.

ANASTASIA, Fátima. Transformando o legislativo: a experiência da Assembléia Legislativa de Minas Gerais. In SANTOS, Fabiano (Org.). O poder legislativo nos estados: diversidade e convergência. Rio de Janeiro: Editora FGV, 2001.

ARAÚJO, Paulo Magalhães. A Assembleia Legislativa de Minas Gerais: divisão de poderes, comportamento parlamentar e produção legislativa entre 1995 e 2010. In: TOMIO, Fabrício; RICCI, Paolo (Orgs.). Governadores e assembleias legislativas: instituições e política nos 
estados brasileiros. São Paulo: Alameda, 2018.

BERG-SCHLOSSER, D.; DE MEUR, G.; RIHOUX, B. e RAGIN, C. Qualitative Comparative Analysis (QCA) as an Approach. In: Configurational Comparative Methods: Qualitative Comparative Analysis (QCA) and Related Techniques, RIHOUX, B. e RAGIN, C. (eds) Sage, Thousand Oaks, CA. 2009.

BORGES, Arleth Santos. Poder legislativo no Maranhão: dinâmicas partidárias e relações com o poder executivo. In: TOMIO, Fabrício; RICCI, Paolo (Orgs.). Governadores e assembleias legislativas: instituições e política nos estados brasileiros. São Paulo: Alameda, 2018.

BRAGA, S; FRANÇA, A. S. Produção legal e relação entre Executivo e Legislativo no Paraná (1999-2002). In: PERISSINOTTO, M.; CODATO, A.; BRAGA, S e; FUCKS, M. (Orgs.). Quem Governa? Um estudo das Elites Políticas do Paraná. Curitiba: UFPR, 2008.

CARREIRÃO, Y; PERONDI, E. Disciplina e coalizões partidárias na Assembléia Legislativa de Santa Catarina (1999-2006). Revista Brasileira de Ciências Sociais, São Paulo, v. 24, n. 71, 2009 p 121-141, out. Disponível em: http://www.scielo.br/pdf/rbcs/v24n71/v24n71a09.pdf. Acesso em: 13 out. de 2020.

CASTRO, M. M., ANASTASIA, F; NUNES, F. Determinantes do comportamento particularista de legisladores estaduais brasileiros. Dados, 52, nº 4, 2009, p. 961-1001.

CERVI, Emerson Urizzi. Produção Legislativa e conexão eleitoral na assembleia legislativa do estado do Paraná. Revista Sociologia e Política, v.17, n. 32, 2009, p. 159-177.

DINIZ, Simone. Interações entre os Poderes Executivo e Legislativo no processo decisório: avaliando sucesso e fracasso presidencial. Dados, vol.48, nº.1, 2005, p. 333-369.

DOMINGUES, Mauro Petersem. Espírito Santo: produção legal e relações entre os poderes Executivo e Legislativo entre 1995 e 1998. In SANTOS, Fabiano (Org.). O poder legislativo nos estados: diversidade e convergência. Rio de Janeiro: Editora FGV, 2001.

GRAÇA, Luís Felipe Guedes da. Vetos e derrubadas: por que são importantes? In: GRAÇA, Luís Felipe Guedes da. O governo do Estado e a Assembleia Legislativa: entre a submissão e os limites da independência. Curitiba: Editora Appris, p. 229-244, 2016.

GRAÇA, Luís Felipe Guedes da; PINTO, Alexandre Alves. A relação dos poderes executivolegislativo no estado do Rio de Janeiro (2003-2010). In: TOMIO, Fabrício; RICCI, Paolo (Orgs.). Governadores e assembleias legislativas: instituições e política nos estados brasileiros. São Paulo: Alameda, 2018.

GROHMANN, Luis Gustavo. O processo legislativo no Rio Grande do Sul: 1995 a 1998. In SANTOS, Fabiano (Org.). O poder legislativo nos estados: diversidade e convergência. Rio de Janeiro: Editora FGV, 2001.

GURGEL, Maria Cristina do Amaral; VASCONCELOS, Flávio Carvalho de. Configurações Estratégicas de Firmas Brasileiras de Alto Desempenho Listadas na BM\&FBOVESPA. RAC, vol. 16, $\mathrm{n}^{\circ}$ 4, 2012. pp. 586-607. Disponível em http://www.anpad.Org.br/rac. Data de acesso $22 / 12 / 2015$.

INÁCIO, Magna; AMARAL, Ernesto Friedrich de Lima. Government or Opposition? The Determinants of Legislative Support for Governors in Brazil. Sage Open. September, 2013. Disponível em: http://sgo.sagepub.com/content/3/3/2158244013502492. Data de acesso 13 out. de 2020.

LEITE, Adailton Amaral; SANTOS, Manoel Leonardo. Voto, Parlamento e Políticas Públicas: instituições políticas em Pernambuco. Recife: Editora Universitária da UFPE, 2010.

MAINWARING, S.; SCULLY, T. Introduction: Party Systems in Latin America. In MAINWARING, S. e SCULLY, T. Building Democratic Institutions: Party Systems in Latin America. Stanford: Stanford University Press, 1995. 
MELO, Carlos Ranulfo. Individualismo e partidarismo em doze estados brasileiros. Revista Brasileira de Ciências Sociais, v. 26, nº75, 2011, p. 57-71.

MELO, Carlos Ranulfo. Avaliando vínculos entre partidos e deputados em Assembleias Legislativas Brasileiras. Opinião Pública, Campinas, vol. 21, nº 2, 2015, p. 365-392.

MONTERO, Mercedes; SÁEZ, Manuel Alcántara. Os determinantes do sucesso legislativo presidencial na América Latina: partidos e instituições. In: INÁCIO, Magna e RENNÓ, Lucio (Orgs.). Legislativo brasileiro em perspectiva comparada. Belo Horizonte: Editora UFMG. 2009.

MORAES, Filomeno. A dinâmica legislativa na Assembléia do estado do Ceará: 1995 a 1998. In SANTOS, Fabiano (Org.). O poder legislativo nos estados: diversidade e convergência. Rio de Janeiro: Editora FGV, 2001.

NUNES, Felipe. Convergência partidária e base parlamentar: o comportamento dos partidos na Assembléia Legislativa de Minas Gerais entre 1995 e 2005. Cadernos da Escola do Legislativo, v. 10, n. 15. 2008. pp. 83-130.

NUNES, Felipe. Coalizões legislativas estaduais: uma análise comparativa dos governos de Minas Gerais e Rio Grande do Sul entre 1998-2006. Teoria e Sociedade, n. 19.2, 2011, p. 40-79.

NUNES, Felipe. What is the Best Strategy to Obtain Legislative Support? Survey Evidence from Brazilian State Assemblies. Brazilian Political Science Reiew, v. 6, n. 2, 2012, p. 88-113. Disponível em: https://www.scielo.br/pdf/bpsr/v6n2/a04v6n2.pdf. Acessado em 10 out. 2020.

NUNES, Felipe. Os determinantes dos resultados de soma positiva em Minas Gerais e no Rio Grande do Sul. Revista de Sociologia e Política, Curitiba, v. 21, n. 47, p. 89-110, 2013.

PÉREZ-LIÑAN, Aníbal. El método comparativo y el análisis de configuraciones causales. Revista Latinoamericana de Política Comparada, v. 13, n. 3, 2010, p. 125-148.

RAGIN, Charles C. The comparative method: Moving beyond qualitative and quantitative estrategies. Berkeley: University of California Press, 1987.

RAGIN, Charles C. Redesigning social inquiry: Fuzzy sets and beyond. Chicago: University of Chicago Press, 2008.

RAINHA, Jamila. Espírito Santo: dinâmica partidária, produção legal e relação entre os poderes Executivo e Legislativo entre 2003-2010. In: TOMIO, Fabrício; RICCI, Paolo (Orgs.). Governadores e assembleias legislativas: instituições e política nos estados brasileiros. São Paulo: Alameda, 2018.

RIHOUX, B. e RAGIN, Charles. C. (Org.). Configurational comparative methods: Qualitative comparative analysis (QCA) and related techniques. Thousand Oaks, CA: Sage, 2009.

SANDES-FREITAS, Vítor; BIZARRO NETO, Fernando. Qualitative Comparative Analysis (QCA): usos e aplicações do método. Revista Política Hoje, v. 24, nº 2, 2015, p. 103-117.

SANDES-FREITAS, Vítor E. V. de; MASSONETTO, Ana Paula. (Ultra)presidencialismo de coalizão estadual: uma análise a partir dos casos de São Paulo e Piauí (1995-2010). Cadernos Adenauer - Poder Legislativo sob múltiplos olhares, ano XVIII, nº ${ }^{\circ}$. Rio de Janeiro: Fundação Konrad Adenauer, 2017.

SANTOS, Fabiano. O poder legislativo nos estados: diversidade e convergência. Rio de Janeiro: Editora FGV, 2001a.

SANTOS, Fabiano. A dinâmica legislativa no estado do Rio de Janeiro: análise de uma legislatura. In SANTOS, Fabiano (Org.). O poder legislativo nos estados: diversidade e convergência. Rio de Janeiro: Editora FGV, 2001b.

SANTOS, Fabiano; GRAÇA, L. F. G. Uma análise da produção legislativa durante os dois primeiros anos do governo Sérgio Cabral: indicadores quantitativos e qualitativos em uma perspectiva comparativa. Relatório de Pesquisa, 2009. Disponível em: http:// 
www.fazenda.rj.gov.br/sefaz/content/conn/UCMServer/uuid/dDocName\%3A982105. Acessado em $15 / 07 / 2015$.

SANTOS, Manoel Leonardo; PÉREZ-LIÑÁN, Aníbal; MONTERO, Mercedes García. El control presidencial de la agenda legislativa en América Latina. Revista de Ciência Política. vol 34, n. 3, 2014, p. 511-536.

SANTOS, Manoel Leonardo; ANASTASIA, Fátima (Orgs.). Política e desenvolvimento institucional no legislativo de Minas Gerais. Belo Horizonte: Editora PUC Minas, 2016.

SILAME, Thiago. Assembleias Legislativas de Minas Gerais, Rio de Janeiro e Rio Grande do Sul: política de recrutamento para as comissões permanentes. Curitiba: Editora Appris, 2018.

TOMIO, Fabricio; MIRANDA, Eduardo Soncini. Paraná, Santa Catarina e Rio Grande do Sul: muitas constantes e poucas variações no processo legislativo estadual na Região Sul (1983-2013). TOMIO, Fabrício; RICCI, Paolo (Orgs.). Governadores e assembleias legislativas: instituições e política nos estados brasileiros. São Paulo: Alameda, 2018a.

TOMIO, Fabrício e RICCI, Paolo. Instituições e decisões: estudo comparativo do processo legislativo nas Assembleias Estaduais. In: $7^{\circ}$ Encontro da ABCP, 2010, Recife - PE. Anais. Recife: ABCP, 2010.

TOMIO, Fabrício e RICCI, Paolo. Seis décadas de processo legislativo estadual: processo decisório e relações Executivo/Legislativo nos estados (1951-2010). Cadernos da Escola do Legislativo, v. 13, n. 21, p.48-61, 2012a.

TOMIO, Fabrício e RICCI, Paolo. O governo estadual na experiência brasileira: os desempenhos legislativos das assembléias estaduais. Revista Sociologia e Política, v. 21, n. 41, 2012b.

TOMIO, Fabrício e Paolo, RICCI. Governadores e Assembleias Legislativas: instituições e política nos estados brasileiros. São Paulo: Alameda, 2018a.

TOMIO, Fabrício; RICCI, Paolo. A produção legislativa nas Assembleias legislativas estaduais. TOMIO, Fabrício; RICCI, Paolo (Orgs.). Governadores e assembleias legislativas: instituições e política nos estados brasileiros. São Paulo: Alameda, 2018b.

WAGEMANN, C. Qualitative Comparative Analysis (QCA) and Fuzzy Sets, Applications and Perspectives for a Mixed Methods Strategy, Estudio Working Paper 142, Universidad Autónoma de Madrid Working Papers Online Series, 2012 http://www.uam.es/wpcpolitica. Acesso em 01/10/2015.

Artigo recebido em: 2020-11-11

Artigo reapresentado em: 2020-12-09

Artigo aceito para publicação em: 2020-12-10 